\section{Debate Debate}

\section{Baltica Beatriz} Cabieses Valdes

Universidad del Desarrollo, Chile

E-mail: bcabieses@udd.cl
O artigo "Educación y su relación con ingreso y salud: Una reflexión acerca de la desigualdad en Chile" tem uma proposta interessante, introduzindo um debate que não é exclusivo do Chile. Melhor considerá-lo como típico de nossos dias, num mundo globalizado e movido pelo interesse do capital financeiro e não pelos mais respeitáveis desígnios da humanidade.

A Autora parte da mobilização estudantil no Chile, mas é notável a maneira como o descontentamento, especialmente entre os jovens, tem se espalhado em diferentes países, sempre com mobilização pelas redes sociais. As questões relacionadas com privatização e desigualdade remetem, inevitavelmente, a pensar em políticas de cotas no contexto das "ações afirmativas". A menção à solidariedade e equidade e à seleção natural, remete às idéias de Peter Singer e sua redescoberta de uma "esquerda darwinista".

Da mesma forma, a menção ao estado de bem-estar social nos faz pensar não apenas no Chile e na América Latina. Basta ver o que ocorre no continente europeu, berço deste "welfare state".

Mas, sobretudo, o artigo remete a uma discussão que envolve as duas conferências globais que tiveram como sede o Rio de Janeiro: a de "Determinantes Sociais em Saúde" e a "RIO mais 20". A primeira teve, além das conclusões finais oficiais, dois outros relatórios "da sociedade", bem mais radicais e afirmativos. A segunda apresentou um pífio relatório final, fruto da dificuldade de entendimento entre países pobres e países ricos quanto a quem deve pagar a conta das ações que garantam um "desenvolvimento sustentável".

Enfim, este artigo dá margem a um debate proveitoso, ouvidas opiniões diversas e divergentes,

A Revista Brasileira de Epidemiologia tem a tradição de promover debates que tratem de questões polêmicas em saúde, como este. Neste caso, propõe abrir este debate a seus leitores, mediado por um Editor Associado e colhendo opiniões de especialistas convidados e dos leitores em geral*, sempre com a participação da Autora do artigo.

José da Rocha Carvalheiro Editor Associado Faculdade de Medicina de Ribeirão Preto da Universidade de São Paulo

* Contribuições em Português, Inglês ou Espanhol

* Contributions in English, Portuguese or Spanish

* Contribuciones en español, portugués o inglés

\title{
Educación y su relación con ingreso y salud: Una reflexión acerca de la desigualdad en Chile
}

Desde mayo de 2011, Chile ha presentado la mayor movilización estudiantil conocida en su historia, enteramente liderada por estudiantes universitarios. Estas movilizaciones han surgido por un rechazo al sistema educacional chileno, que provee una amplia participación del sector privado respecto al Estado. Actualmente, solo el $25 \%$ del sistema educativo es financiado por el Estado, mientras que los estudiantes aportan el otro $75 \%^{1}$. Este movimiento estu- diantil es un proceso democrático, pacífico y con fuertes raíces en el creciente descontento de la sociedad chilena respecto de las desigualdades sociales existentes.

Una reciente discusión nacional entre líderes de los estudiantes y el gobierno ha generado especial debate. Para los estudiantes la educación es un bien social, que promueve el bienestar no sólo de aquellos mejor educados, sino también de aquellos que no accedieron a tal formación, pero 
que se beneficiarían del crecimiento y desarrollo global de Chile. A la base de este argumento está el principio de solidaridad, ya que los estudiantes proponen que la educación universitaria debiera ser fundamentalmente costeada por medio de impuestos, pagados incluso por aquellos que no tendrán formación universitaria durante su vida. Un interesante contra-argumento del gobierno y de líderes de instituciones universitarias es que es injusto pedir a los más desfavorecidos del país que financien la educación de unos pocos privilegiados. El propósito de esta carta es invitar a una reflexión más abierta y acabada sobre la educación como un determinante social central de la salud. Para ello, destaca la importancia de analizar la educación en forma integrada con otros determinantes sociales, fundamentalmente ingreso y salud. Esta reflexión podría aportar al debate actual en torno a cuál es el rol de la educación en la salud y bienestar de todos los chilenos.

Existe amplio conocimiento acerca de la estrecha relación entre educación y salud. Múltiples estudios en todos los continentes del mundo demuestran que a mayor nivel de educación existe mayor bienestar, sobrevida y calidad de vida. Existe de hecho un fino gradiente en salud que indica que por cada año adicional de educación, mayores son los beneficios en salud en las personas. En Chile esto no es distinto. A mayor educación mejores hábitos de vida (excepto por tabaquismo $)^{2}$, menor prevalencia de enfermedades y mayor bienestar general ${ }^{3}$. En conocimiento de esta evidencia, y también por sentido común, toda la sociedad chilena apoya el proceso actual de reforma a la educación liderada por estudiantes universitarios.

Conforme a los lineamientos de la nueva movilización estudiantil, mejorar la educación en Chile hoy implica necesariamente destinarle mayores fondos desde el sector público, por medio de los impuestos. Dicha alternativa es razonable sólo si se le acompaña de una reforma social al ingreso de las familias. En efecto, obligar a los más pobres en Chile a financiar la educación de quienes hoy tienen más acceso al nivel universitario sólo dependiente de su cuna de origen, es una enorme injusticia si se toma como medida única. Las clases media y baja, que logran usualmente el nivel primario y técnico de educación, estarían con su trabajo financiando la educación de la clase socioeconómica más rica. Esto, a la larga, produciría mayores diferencias en el ingreso, por un efecto simultáneo de aumento de los impuestos en los pobres y la "selección natural" de aquellos mejor educados a nivel secundario (quienes pudieron costear una educación escolar que los preparó mejor para la universidad).

Si esta medida se llevara a cabo en forma aislada, los efectos en salud de un aumento de las desigualdades en educación e ingreso económico en Chile podrían ser nefastos. Existen múltiples argumentos que dan cuenta de estos daños, y en este documento presentaré tres principales. En primer lugar, una baja educación determina en Chile un ingreso económico sostenidamente bajo para dichas familias. Una persona con sueldo mínimo o menor hoy se enfrenta a un problema de pobreza material absoluta que pone en riesgo su salud. Peor aún, la mayoría de las familias pobres cuentan con un elevado número de niños que crecen en viviendas gravemente insuficientes para su normal desarrollo y crecimiento. Hacinamiento, frío, calefacción inadecuada, ruido, exposición a asbesto, entre muchos otros factores asociados a pobreza material, producen un grave efecto en la salud de quienes viven en esas condiciones. Además, dañan la salud de nuestras futuras generaciones.

Al mismo tiempo, familias de clase baja y media en Chile son sometidas a estrés crónico durante su vida. Esto afecta a la inmensa mayoría de la población, incluyendo no sólo a los más pobres sino a todos quienes no están en el grupo selecto más rico de Chile. De hecho, los efectos de la desigualdad relativa en el ingreso pueden ser enormes. En un país con el crecimiento económico como Chile, existe la alternativa de redistribuir el ingreso y la reforma educacional puede ser clave en este proceso. Redistribución en el ingreso, 
levantando el sueldo mínimo y generando un debate social sobre un posible límite de sueldo en Chile (tal como se ha propuesto en otros países desarrollados), son puntos pendientes de debatir en el contexto de la reforma educacional para prevenir una profundización de las desigualdades entre grupos socioeconómicos a lo largo del tiempo ${ }^{4}$.

Tercero, se ha debatido ampliamente un efecto de selección directa e indirecta de la educación en las oportunidades de trabajo, ingreso, condiciones laborales y capacidad de control y autonomía del propio trabajo, entre otros. Estos son factores que afectan de manera importante la salud de cualquier trabajador a lo largo de su vida. Familias pobres en Chile no pueden financiar una educación de calidad para sus hijos, y como consecuencia ellos no logran desarrollar todas sus potencialidades, no se siguen capacitando y perpetúan un reconocido ciclo inter-generacional de pobreza. Romper estos ciclos de pobreza es también un desafío pendiente en Chile que debe ser considerado en la actual reforma a la educación.

En conclusión, este documento propone que la actual reforma educacional en Chile es urgente pero debe ser acompañada de otros procesos simultáneos, para evitar el riesgo de que, con buenas intenciones, se incrementen las desigualdades en el ingreso, beneficiando en forma exagerada a algunos pocos y manteniendo en pobreza a una gran porción de la población. Chile requiere iniciar un debate sobre cómo debemos redistribuir el ingreso en nuestra sociedad. Estas medidas, acompañadas con las medidas a la educación que mejoren radicalmente la formación escolar pública y acaben con el lucro en la educación universitaria, podrían transformar nuestra sociedad en una sociedad más justa, solidaria, democrática, saludable y feliz.

\section{Agradecimiento}

Al Dr. Manuel Espinoza por sus comentarios a una versión anterior de este documento.

\section{Referencias}

1. Smink, Verónica (Miércoles, 10 de agosto de 2011). Las razones de las protestas estudiantiles en Chile. $B B C$ Mundo. Consultado el 25 de agosto de 2011.

2. Cabieses B, Espinoza MA, Zitko P. How to deal with increased individual risk behaviors in Chile? Rev Medica de Chile 2011; 139: 686-8.
3. Ministerio de Salud de Chile (MINSAL). Plan Nacional de Salud para el cumplimiento de los Objetivos Sanitarios de la Década 2011-2020. Documento preliminar a difundir prontamente en www.minsal.cl.

4. Wilkinson RG, Pickett K. The Spirit Level, Why More Equal Societies Almost Always Do Better. United Kingdom: Penguin; 2009. 